\title{
Bioactive Hydrogels: Design and Characterization of Cellulose-Derived Injectable Composites
}

\author{
Andrea Fiorati ${ }^{1,2, *(1)}$, Cristina Linciano ${ }^{1}$, Camilla Galante ${ }^{1}$, Maria Grazia Raucci ${ }^{3}\left(\mathbb{C}\right.$ and Lina Altomare ${ }^{1,2} \mathbb{( D )}$ \\ 1 Department of Chemistry, Materials, and Chemical Engineering "G. Natta"—Politecnico di Milano, Piazza \\ Leonardo da Vinci 32, I-20133 Milano, Italy; cristina.linciano@mail.polimi.it (C.L.); \\ camilla.galante@mail.polimi.it (C.G.); lina.altomare@polimi.it (L.A.) \\ 2 INSTM National Interuniversity Consortium of Materials Science and Technology, Politecnico di Milano \\ Local Unit, Piazza Leonardo da Vinci 32, I-20133 Milano, Italy \\ 3 Institute of Polymers, Composites and Biomaterials (IPCB), National Research Council (CNR), Viale J.F. \\ Kennedy, 54 Mostra d'Oltremare Pad. 20, 80125 Naples, Italy; mariagrazia.raucci@cnr.it \\ * Correspondence: andrea.fiorati@polimi.it
}

Citation: Fiorati, A.; Linciano, C.; Galante, C.; Raucci, M.G.; Altomare, L. Bioactive Hydrogels: Design and Characterization of Cellulose-Derived Injectable Composites. Materials 2021, 14, 4511. https://doi.org/10.3390/ ma14164511

Academic Editors: Shanfeng Wang, Lichun Lu and Michael J. Yaszemski

Received: 29 June 2021

Accepted: 8 August 2021

Published: 11 August 2021

Publisher's Note: MDPI stays neutral with regard to jurisdictional claims in published maps and institutional affiliations.

Copyright: (c) 2021 by the authors. Licensee MDPI, Basel, Switzerland. This article is an open access article distributed under the terms and conditions of the Creative Commons Attribution (CC BY) license (https:// creativecommons.org/licenses/by/ $4.0 /)$.

\begin{abstract}
Cellulose represents a low cost, abundant, and renewable polysaccharide with great versatility; it has a hierarchical structure composed of nanofibers with high aspect ratio (3-4 nm wide, hundreds of $\mu \mathrm{m}$ long). TEMPO-mediated oxidation represents one of the most diffused methods to obtain cellulose nanofibers (CNFs): It is possible to obtain physically crosslinked hydrogels by means of divalent cation addition. The presence of inorganic components, such as calcium phosphates $(\mathrm{CaP})$, can improve not only their mechanical properties but also the bioactivity of the gels. The aim of this work is to design and characterize a TEMPO-oxidized cellulose nanofibers (TOCNFs) injectable hydrogel embedded with inorganic particles, $\mathrm{CaP}$ and $\mathrm{CaP}-\mathrm{GO}$, for bone tissue regeneration. Inorganic particles act as physical crosslinkers, as proven by rheological characterization, which reported an increase in mechanical properties. The average load value registered in injection tests was in the range of 1.5-4.4 N, far below $30 \mathrm{~N}$, considered a reasonable injection force upper limit. Samples were stable for up to 28 days and both $\mathrm{CaP}$ and $\mathrm{CaP}-\mathrm{GO}$ accelerate mineralization as suggested by SEM and XRD analysis. No cytotoxic effects were shown on SAOS-2 cells cultured with eluates. This work demonstrated that the physicochemical properties of TOCNFs-based dispersions could be enhanced and modulated through the addition of the inorganic phases, maintaining the injectability and bioactivity of the hydrogels.
\end{abstract}

Keywords: TEMPO-oxidized nanocellulose; hydrogel; biocomposite; mineralization; hydroxylapatite

\section{Introduction}

Hydrogels are macromolecular polymeric materials that are crosslinked to form a 3-D network. They are able to retain relatively large volumes of water, without solubilization in an aqueous environment and have assumed increasing interest as scaffolds for tissue regeneration support due to their tunable properties. Moreover they are able to mimic the extracellular matrix environment, and, when combined with specific compounds that enhance their mechanical properties, might give rise to a biocomposite able to cover many applications in the biomedical field [1-4].

Natural polymer-based hydrogels, properly crosslinked through chemical or physical bonds, allow us to obtain a biocompatible and three-dimensional structure whose mechanical properties and degradation kinetics can be modulated in different ways and targeted to a specific application [5]. Among natural polymers, cellulose represents a low cost, abundant and renewable polysaccharide with great versatility [6-8].

Generally, cellulose chains are assembled into hierarchical fibrillary architectures which can be disassembled into nanometric dimensioned fibers [6,9]. Among all the different methods to obtain cellulose nanofibers (CNFs) proposed in the literature, the selective 
oxidation of C6 cellulose hydroxyls catalyzed by the stable radical 2,2,6,6-Tetramethyl-1piperidinyloxy (TEMPO) represents one of the most diffused approaches [10-14]. From TEMPO-oxidized CNFs (TOCNFs) aqueous dispersions it is possible to obtain physically crosslinked hydrogels by means of divalent cation addition [15-18]. Recently, cellulose and its derivative have been widely investigated leading to different applications in the biomedical field [19]. Even though cellulose by itself does not present specific adhesion sites, this material can be easily modified by blending, functionalization or by incorporating inorganic particles. For all these reasons, cellulose-based biomaterials offer some important advantages and lead to different applications in the biomedical field, such as tissue regeneration and drug delivery, and have been widely studied, demonstrating cellulose biocompatibility, cytocompatibility and mechanical stability $[15,20]$.

The main disadvantage of the physical crosslinked hydrogels is their lack of mechanical properties [10]. The realization of biocomposite hydrogels through inorganic particles incorporation can help in overcoming this drawback. Hydroxyapatite and its precursors $(\mathrm{CaP})$, and graphene-oxide (GO) have been widely investigated as bioactive fillers for polymer matrices. HA has attracted increasing attention as a substitute material for bone thanks to its crystallographic similarity to calcified human tissues; it can be retrieved from natural sources or be synthesized with high variability in purity, ratio of amorphous to crystalline phase, particles size and distribution [21]. Moreover, its bioactivity makes it a suitable material to realize biocomposites that enhance mineralization, cell attachment and migration [22].

The high functionalization of the GO surface enhances its biocompatibility and facilitates its incorporation in polymer matrix [23]. This structure provides binding sites that improve cell adhesion and promote stem cell differentiation processes, particularly adipogenesis and osteogenesis. GO is proposed as an ideal reinforcing material that can be used to strengthen and toughen HA without compromising its bioactivity and biocompatibility thanks to its high chemical inertness [24]. GO has also shown antibacterial features and has been tested as an effective treatment for cancer as it can specifically target cancer cells with a significant cytotoxic effect against osteosarcoma [25].

Depending on the specific application, cellulose-based hydrogel can be combined with different composites enhancing its specific properties. In particular, it has been demonstrated that the incorporation of inorganic particles, such as HA and GO, can improve its mechanical and bioactive properties [24].

In this work, TEMPO-oxidized cellulose nanofibers (TOCNFs) hydrogels embedded with inorganic particles were prepared, as shown in Figure 1. Their formulation was chosen in order to achieve an injectable and bioactive matrix for bone tissue regeneration. In particular, the injectability was studied firstly by means of a rheological characterization, and then exploiting an ad hoc developed setup able to measure the force needed to extrude the biocomposites loaded in a syringe equipped with an $18 \mathrm{G}$ needle. After we verified that the obtained hydrogels were suitable for our purpose, in vitro assays were performed in order to investigate their behavior in terms of swelling, ability to mineralize, and release of cytotoxic components. 

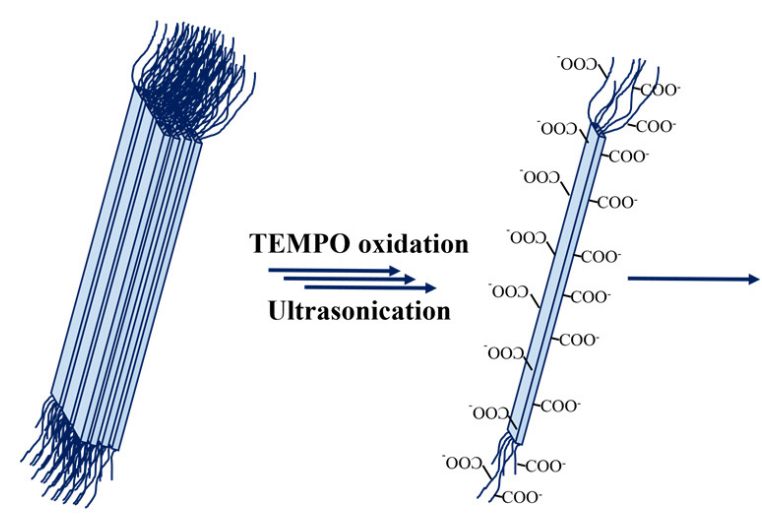

Cellulose
TEMPO oxidized cellulose nanofiber

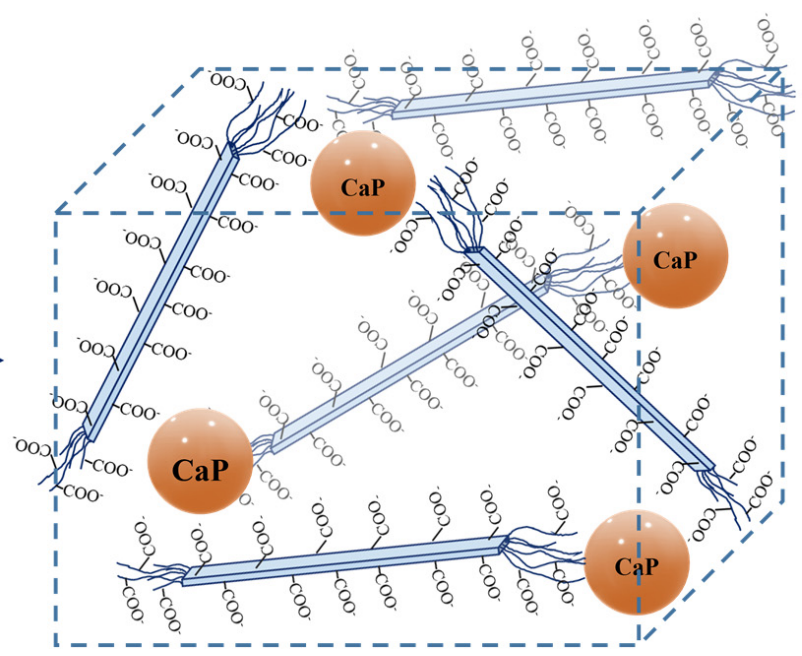

Injectable hydrogel

Figure 1. Schematic representation of the production of TOCNFs-CaP/CaPGO hydrogels. The pristine cellulose was converted to TEMPO oxidized cellulose nanofibers by means of TEMPO/KBr/ $\mathrm{NaClO}$ oxidative system followed by an ultrasonic assisted dispersion. Inorganic particles were added to the achieved dispersion in order to induce the sol-gel transition.

\section{Materials and Methods}

All chemicals were commercially available and were provided by Merck Life Science S.r.l. (Milan, Italy). For this study Sigmacell (Lot No. SLBZ6032) was chosen as cotton linter cellulose standard. Sodium hypochlorite solution Lot No. K52670914 031.

\subsection{Composite Hydrogels Preparation}

\subsubsection{Oxidized Cellulose Synthesis}

Oxidized cellulose was obtained as described in the literature [10,12]. Briefly, $0.538 \mathrm{~g}$ of TEMPO (3.44 mmol) and $3.70 \mathrm{~g}$ of $\mathrm{KBr}(31.1 \mathrm{mmol})$ were dissolved in deionized (DI) water $(1 \mathrm{~L})$ under magnetic agitation. Then this solution was added to a dispersion of cellulose ( $25 \mathrm{~g}$ in $375 \mathrm{~mL}$ of water) under vigorous stirring. Sodium hypochlorite solution (125 mL, 6-14\% active chlorine) was gradually added in $1 \mathrm{~h}$ under stirring. During the reaction, the $\mathrm{pH}$ was continuously monitored and maintained in the range of 10.5-11.0 through the progressive addition of $\mathrm{NaOH}$ solution $(2 \mathrm{M}$, about $100 \mathrm{~mL}$ ). After keeping it under constant stirring for $16 \mathrm{~h}, \mathrm{HCl}$ solution $(2 \mathrm{M})$ was added until $\mathrm{pH} 2$ was reached. The oxidized cellulose pulp was collected by filtration on a Büchner and extensively washed with HClaq $(0.01 \mathrm{M}, 3 \times 0.5 \mathrm{~L})$, water $(3 \times 0.5 \mathrm{~L})$ and ethanol $(4 \times 0.5 \mathrm{~L})$. The obtained oxidized cellulose was then dried in an oven at $37^{\circ} \mathrm{C}$ for $24 \mathrm{~h}$.

The number of acidic moieties introduced was evaluated by means of colorimetric titration employing $\mathrm{NaOH}_{\mathrm{aq}}(0.1 \mathrm{M})$ and phenolphthalein as indicator. The oxidation degree was $2.13 \mathrm{mmol} \mathrm{COOH} / \mathrm{g}_{\text {cellulose }}$.

\subsection{2. $\mathrm{CaP}$ and $\mathrm{CaPGO}$ Particles Synthesis}

$\mathrm{CaP}$ particles, with and without $\mathrm{GO}$, were produced at room temperature by sol-gel technology as previously reported [24]. In brief, calcium nitrate tetrahydrate $\left[\mathrm{Ca}\left(\mathrm{NO}_{3}\right)_{2} \cdot 4 \mathrm{H}_{2} \mathrm{O}\right]$ and di-ammonium phosphate $\left[\left(\mathrm{NH}_{4}\right)_{2} \mathrm{HPO}_{4}\right]$, at $\mathrm{Ca} / \mathrm{P}$ molar ratio in the range of 1.60-1.70 were used as precursors of $\mathrm{Ca}^{2+}$ and $\mathrm{PO}_{4}{ }^{3-}$ respectively. The preparation of CaPGO particles was obtained by adding GO (Nanesa srl, Arezzo, Italy, 1.5 wt. \%) during CaP in situ sol-gel synthesis. In particular, GO exfoliation was performed in distilled water $\left(\mathrm{dH}_{2} \mathrm{O}\right)$ by sonication in ultrasound bath for several hours. Then, GO solution (1.5 wt. \%) was added in $\mathrm{Ca}^{2+}$ solution $(3 \mathrm{M})$ in order to improve the interactions between calcium ions and 
chemical groups on the GO surface. After $30 \mathrm{~min}$ of magnetic mixing at room temperature, $\mathrm{PO}_{4}{ }^{3-}$ solution $(3.58 \mathrm{M})$ was gradually added and the $\mathrm{pH}$ was set to $\mathrm{pH} 10-11$ by $\mathrm{NH}_{4} \mathrm{OH}$ solution. After gelification, the system was washed several times to remove some residues of reaction, such as ammonium nitrate $\left(\mathrm{NH}_{4} \mathrm{NO}_{3}\right)$, and then was freeze-dried for 2 days to obtain the powders.

\subsubsection{Composite Hydrogels Synthesis}

A TOCNFs stock dispersion $\left(4 \% \mathrm{w} \mathrm{w}^{-1}\right)$ was prepared as follows: $2.0 \mathrm{~g}$ of oxidized cellulose were weighed in a beaker and dispersed in DI water (about $30 \mathrm{~mL}$ ), then 1 equivalent of $\mathrm{NaOH}_{\mathrm{aq}}(2 \mathrm{M})$ with respect to the content of carboxylic groups was added. Then, the slurry was sonicated using a sonic dismembrator (FB-505, Fisherbrand, $6 \mathrm{~mm}$ probe tip working in alternated mode ( $40 \mathrm{~s}$ on, $10 \mathrm{~s}$ off), with an output power of $40 \%$ the nominal value $(200 \mathrm{~W})$, until the dispersion appears clear and transparent (approximately $40 \mathrm{~min}$ ). The overheating of the dispersion was prevented by means of an ice bath. When the dispersion was achieved, the $\mathrm{pH}$ was set to 7.4 by means of $\mathrm{NaOH}_{\mathrm{aq}}(0.1 \mathrm{M})$, the weight was adjusted to $50 \mathrm{~g}$ with DI water and then was autoclaved at $121^{\circ} \mathrm{C}$ for $20 \mathrm{~min}$.

The specimens were prepared by mixing the stock solution and the inorganic particles dispersed in DI water, as summarized in Table 1. The inclusion process was conducted in a sterile environment by loading the two components into two different sterile syringes connected by means of a three-way Luer Stopcock and then mixing them with 50 passes between syringes until the particles homogeneously spread in the suspension.

Table 1. Specimen's details.

\begin{tabular}{ccccc}
\hline Sample ID & $\begin{array}{c}\text { TOCNFs Dispersion } \\
{[\mathbf{m g}]}\end{array}$ & $\begin{array}{c}\text { HA } \\
{[\mathbf{m g}]}\end{array}$ & $\begin{array}{c}\text { HAGO } \\
{[\mathbf{m g}]}\end{array}$ & $\begin{array}{c}\text { Deionized Water } \\
{[\boldsymbol{\mu L}]}\end{array}$ \\
\hline TOCNFs_CaP & 445 & 5 & - & 50 \\
TOCNFs_CaPGO & 445 & - & 5 & 50 \\
TOCNFs & 445 & - & - & 55 \\
\hline
\end{tabular}

\subsection{Characterizations}

\subsubsection{FTIR and XRD Analyses}

Fourier transform infrared spectroscopy (FT-IR) was conducted using infrared-grade $\mathrm{KBr}$ disks and a Varian 640-IR spectrometer (Agilent Technologies, Santa Clara, CA, USA) in the $400-4000 \mathrm{~cm}^{-1}$ range $\left(4 \mathrm{~cm}^{-1}\right.$ resolution, 32 scans).

X-ray diffraction (XRD) experiments were performed with Panalytical Empyrean diffractometer (Malvern Panalytical Ltd., Malvern, UK) equipped with a Bragg Brentano geometry $(\mathrm{Cu}-\mathrm{K} \alpha 1$ radiation; $\lambda=0.154056 \mathrm{~nm})$. The $X$-ray diffraction patterns were collected in 0-80 $2 \theta$ range (scan step size $=0.02^{\circ}$, scanning time as per step $=20 \mathrm{~s}$, room temperature). Each measurement was performed in triplicate in order to increase the signal-to-noise ratio. XRD patterns were analyzed using Profex Software [26].

\subsubsection{Thermal Analyses}

Thermogravimetric analysis (TGA) and differential Thermal Analysis (DTA) were carried on with Perkin Elmer STA 6000 (Perkin Elmer Italia S.p.A, Milan, Italy) on freezedried TOCNFs hydrogels samples employing a heating ramp of $10^{\circ} \mathrm{C} \mathrm{min}{ }^{-1}$ in the range of $30-900{ }^{\circ} \mathrm{C}$, under air conditions.

\subsubsection{Morphological Characterization}

The morphology and microstructure of freeze-dried TOCNFs hydrogels pre- and postmineralization assays were observed under a Zeiss EVO 50 EP (Carl Zeiss Microscopy Gmb, Jena, Germany) scanning electron microscope (SEM) equipped with a Bruker Quantax 200 6/30 detector for Energy-dispersive X-ray spectroscopy (EDS) analysis. ETH was set at $20.0 \mathrm{kV}$, I probe ranged from 50 to $100 \mathrm{pA}$ and specimens were observed without gold 
sputter coating, in low vacuum conditions using the back-scattered (BDS) and Variable Pressure Secondary Electron (VPSE) detectors. SEM images were analyzed using ImageJ Software [27].

\subsubsection{Rheological Characterization}

Rheological tests were performed on TOCNFs hydrogels in duplicate using an Anton Paar MCR 302 Modular Compact rheometer (Anton Paar GmbH, Graz, Austria).

The tests were conducted using a parallel plates geometry (diameter $\mathrm{D}=25 \mathrm{~mm}$ ) while the temperature was kept constant at $20{ }^{\circ} \mathrm{C}$. Prior to each measurement, preconditioning was performed at a constant shear strain of $10 \%$ and at molar frequency of $100 \mathrm{~Hz}$ for $1 \mathrm{~min}$ followed by a 2 min rest [28,29].

The rheological properties of the hydrogels were evaluated by means three different experiments: (i) Strain sweep, increasing the shear strain from 0.01 to $100 \%$ with constant frequency at $1 \mathrm{~Hz}$ in order to determinate the linear viscoelastic range (LVR) of the material (Figure S1). The strain value (10\%) was selected in order to optimize the signal-to-noise ratio for the following experiments; (ii) frequency sweep, increasing the frequency from 0.01 to $100 \mathrm{~Hz}$ with $10 \%$ of strain; (iii) shear rate sweep, increasing the shear rate from 0.1 to $1000 \mathrm{~s}^{-1}$.

\subsubsection{Injectability Test}

Injectability tests were performed following a custom experimental setup (Figure S2) coupled to a uniaxial tensile testing machine (MTS 1/MH, load cell $5 \mathrm{kN}$, MTS Systems, Eden Prairie, MN, USA) in compression mode. The setup consists of a Poly(methyl methacrylate) cylinder perforated in order to accommodate the syringe allowing the maintenance of the vertical position and the alignment to the testing machine plate. Underneath the syringe needle, a container is positioned to collect the extruded sample.

Hydrogels were loaded inside a new, sterile $5 \mathrm{~mL}$ syringe and extruded through an $18 \mathrm{G}$ needle. The syringe was mounted on the predefined setup; the plate was first gradually approached to the syringe piston at a speed of $1 \mathrm{~mm} \mathrm{~min}^{-1}$ until a load of $0.15 \mathrm{~N}$ was detected indicating successful contact between the plate and piston. After that, the speed was set to $0.6 \mathrm{~mm} \mathrm{~s}^{-1}$ (corresponding to flow rates of approximately $2.28 \mathrm{~mL} \mathrm{~min}^{-1}$ ) for $15 \mathrm{~mm}$ and the force applied was recorded [30]. At the end of extrusion, the plate was lifted, and the procedure was repeated in duplicate on the same syringe for each TOCNF type extruding another $15 \mathrm{~mm}$ of sample.

The experiment was carried out both on samples immediately after loading in the syringe and on samples that rested inside the syringe for $48 \mathrm{~h}$ in order to evaluate the differences in terms of viscosity and thixotropic characteristics.

Injectability measurements were performed at room temperature $\left(20^{\circ} \mathrm{C}\right)$.

\subsection{In Vitro Test}

\subsubsection{Swelling Test}

The swelling tests were conducted by dipping the samples $(500 \mathrm{mg})$ in sterile Dulbecco's Modified Eagle Medium (DMEM, $4 \mathrm{~mL}$ ) enriched with antibiotic (penicillin and streptomycin $\left.1 \% \mathrm{w} \mathrm{w}^{-1}\right)$ and $0.02 \%\left(\mathrm{w} \mathrm{w}^{-1}\right)$ sodium azide $\left(\mathrm{NaN}_{3}\right)$, in order to prevent microbiological contamination and incubated them at $37^{\circ} \mathrm{C}$. The culture medium was removed, and the samples were weighed at progressive time steps, starting from a 15-min interval for a total of 34 days. Then the hydrogels were covered with $4 \mathrm{~mL}$ of fresh sterile culture medium and stored again in the incubator.

The percentage change in weight $\left(W_{\%}\right)$ was calculated using Equation (1):

$$
W_{\%}=\frac{\left(W_{f}-W_{i}\right)}{W_{i}} \times 100
$$

where, $W_{i}$ is the initial weight of the sample before soaking it in the culture medium, while $W_{f}$ is the weight of the sample following the removal of the medium. 


\subsubsection{In Vitro Mineralization Test}

The apatite formation and bioactivity of the samples were evaluated by simulated body fluid (SBF) treatment. $1.5 \times \mathrm{SBF}$ was prepared according to the method proposed by Kokubo et al. [31]. To prepare $1 \mathrm{~L}$ of SBF solution, $0.5 \mathrm{~L}$ of water was put under continuous stirring in a plastic beaker and heated to $36 \pm 0.5^{\circ} \mathrm{C}$. Then, the following reagents were sequentially dissolved into the solution: $\mathrm{NaCl}(8.035 \mathrm{~g}, 137.5 \mathrm{mmol}), \mathrm{NaHCO}_{3}(0.355 \mathrm{~g}$, $4.2 \mathrm{mmol}), \mathrm{KCl}(0.225 \mathrm{~g}, 3.0 \mathrm{mmol}), \mathrm{K}_{2} \mathrm{HPO}_{4} \cdot 3 \mathrm{H}_{2} \mathrm{O}(0.231 \mathrm{~g}, 1.0 \mathrm{mmol}), \mathrm{MgCl}_{2} \cdot \mathrm{H}_{2} \mathrm{O}(0.311 \mathrm{~g}$, $1.5 \mathrm{mmol}), 1 \mathrm{M} \mathrm{HCl}(39 \mathrm{~mL}), \mathrm{CaCl}_{2}(0.292 \mathrm{~g}, 1.9 \mathrm{mmol}), \mathrm{Na}_{2} \mathrm{SO}_{4}(0.072 \mathrm{~g}, 0.5 \mathrm{mmol})$. When the solution again reached $36 \pm 0.5^{\circ} \mathrm{C}$, Tris (hydroxyl methyl) methyl amine $(6.118 \mathrm{~g}$, $50.5 \mathrm{mmol}$ ) was gradually added. Finally, the $\mathrm{pH}$ was set to 7.4 by addition of $\mathrm{HCl}_{\mathrm{aq}}(1 \mathrm{M})$ then water was added to have $1 \mathrm{~L}$ of SBF solution, which was stored at $4{ }^{\circ} \mathrm{C}$.

For mineralization tests, samples were accurately weighed $(600 \mathrm{mg})$, placed inside a strainer, and immersed in $1.5 \times \mathrm{SBF}(20 \mathrm{~mL})$. Samples were placed in a Shaker Incubator (SKI 4, Argo Lab, Giorgio Bormac S.r.l Carpi MO, Italy) at $50 \mathrm{rpm}, 37^{\circ} \mathrm{C}$ and SBF was renewed every $48 \mathrm{~h}$. The mineralization process was conveyed at four steps: 7, 14, 21 and 28 days. In particular, 21-28 days hydrogels were washed 3 times in water for $10 \mathrm{~min}$ in order to remove $\mathrm{NaCl}$ interferences.

\subsubsection{Cytotoxicity Assay}

Samples were prepared according to the procedure described in par 2.1.3, both TOCNFs and inorganic particles were dispersed in DMEM instead of water.

In order to evaluate the effect of possible release of cytotoxic compounds from hydrogels, in vitro indirect cytotoxicity test was carried out according to EN ISO 10993-12 using SAOS-2 human osteosarcoma cell line. Cells were seeded in 96-well tissue culture polystyrene (TCPS) plates $\left(1 \times 10^{4}\right.$ cells per well) and cultured in DMEM (supplemented by $1 \mathrm{mM}$ sodium pyruvate, $10 \%$ fetal bovine serum, $4 \mathrm{mM}$ L-glutamine, and $1 \%$ penicillinstreptomycin) at $37{ }^{\circ} \mathrm{C}$ in presence of $5 \% \mathrm{CO}_{2}$ humidified atmosphere, until $70 \%$ confluence was reached.

Culture medium eluates were obtained by dipping $200 \mu \mathrm{L}$ of each sample in $1 \mathrm{~mL}$ of medium (time points 1, 3 and 7 days, each time point was repeated four times). Cells were then cultured for $24 \mathrm{~h}$ with culture medium eluates or fresh culture medium. Cell viability was assessed by alamar Blue assay; fluorescence was read by a spectrophotometer (Synergy H1 spectrophotometer, BioTek, Rodano, Italy; $\lambda_{\mathrm{exc}}=540 \mathrm{~nm}, \lambda_{\mathrm{em}}=595 \mathrm{~nm}$ ). The percentage cell viability was calculated according to equation 2 , where $f$ is the fluorescence value of eluates, control and Alamar Blue reference.

$$
\text { Cell viability }[\%]=\frac{f_{\text {eluates }}-f_{\text {AlamarBlue }}}{f_{\text {control }}-f_{\text {AlamarBlue }}} \times 100
$$

\section{Results and Discussion}

3.1. Composite Hydrogels Preparation and Characterization

3.1.1. FT-IR, XRD and Thermogravimetric Analyses

As reported in the literature [14], the TEMPO-oxidation process leads to the formation of carboxyl groups on the cellulose structure which can be easily recognized by observing the presence of the peak at $1731 \mathrm{~cm}^{-1}$, associated with the $\mathrm{C}=\mathrm{O}$ stretching vibration of the carboxylic acids, in the FT-IR spectrum (Figure S3). These moieties, once properly deprotonated, were exploited to achieve the homogeneous dispersions of TEMPO oxidized cellulose nanofibers. Lastly, the carboxylates were employed for the binding with the CaP and CaPGO particles, acting as cross-linker agent. CaP and CaPGO particles, characterized by means of FT-IR spectroscopy and X-Ray Diffraction (Figure S4), were found to be composed of a mixture of brushite, monetite, hydroxyapatite and other calcium phosphates (e.g., calcium pyrophosphate). Despite the greyish appearance of the CaPGO powders (Figure S4a), the typical FT-IR and XRD signals of graphene oxide cannot be clearly detected 
due to the low mass ratio and the overlapping with the phosphate groups (Figure S4b,d), as described in the literature [32].

Thermogravimetric analysis performed on freeze-dried samples (Figure S5) shows in all cases a first small weight loss at about $100{ }^{\circ} \mathrm{C}$ (about $10 \%$ ), which was due to the evaporation of adsorbed water. In the range between $200^{\circ} \mathrm{C}$ and $300^{\circ} \mathrm{C}$, another relevant weight loss was observed in all samples, associated to the decomposition of the organic content. The combustion of the organic carbon residues was observed at $700{ }^{\circ} \mathrm{C}, 600{ }^{\circ} \mathrm{C}$, and $400{ }^{\circ} \mathrm{C}$ respectively for TOCNFs, TOCNFs CaP and TOCNFs CaPGO samples. As expected, the residue at $900{ }^{\circ} \mathrm{C}$ for TOCNFs samples was $0 \%$, while $13.7 \%$ and $13.2 \%$ of residues were obtained for TOCNFs $\mathrm{CaP}$ and TOCNFs CaPGO.

\subsubsection{Rheological Characterization}

The dynamic rheological properties of the hydrogels were investigated at $20^{\circ} \mathrm{C}$ and reported in Figure 2 and Figure S1. Storage modulus $\left(\mathrm{G}^{\prime}\right)$ values remain constant and dominant over loss modulus ( $\left.G^{\prime \prime}\right)$ values up to about $10 \mathrm{~Hz}$ for all the samples. At a specific frequency value, the $G^{\prime}$ and $G^{\prime \prime}$ curves intersect, showing a more liquid-like behavior of the hydrogels.

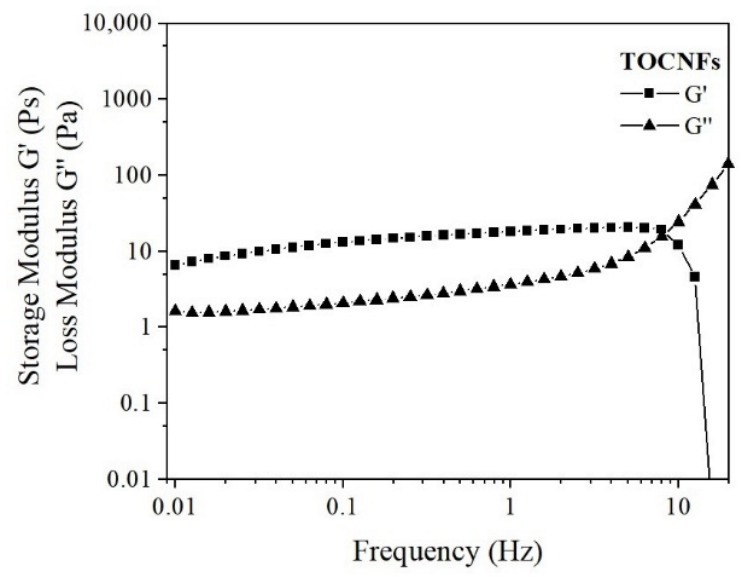

(a)

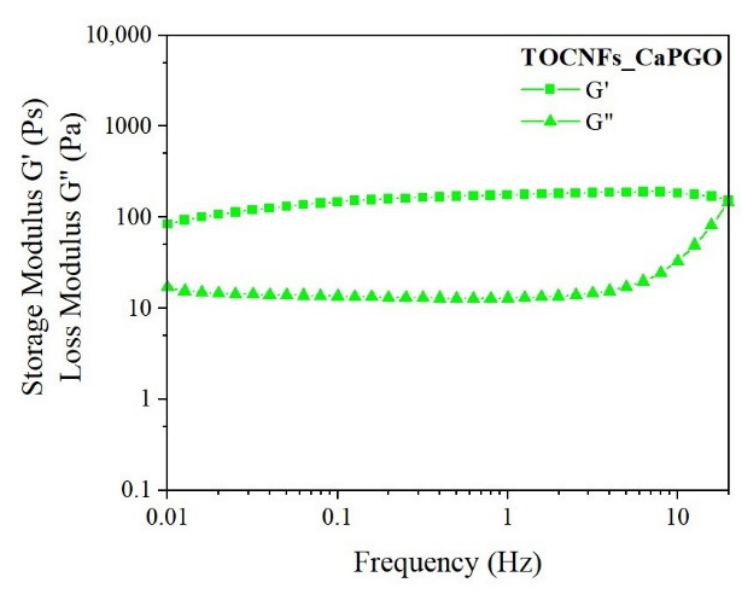

(c)

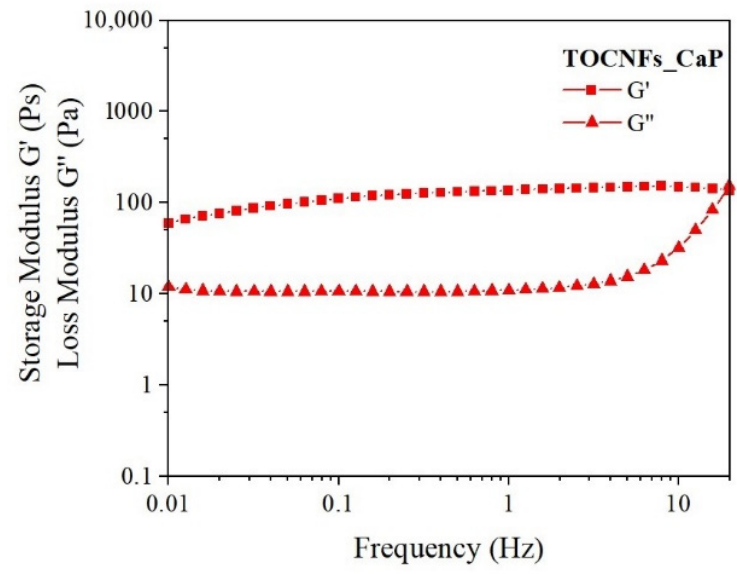

(b)

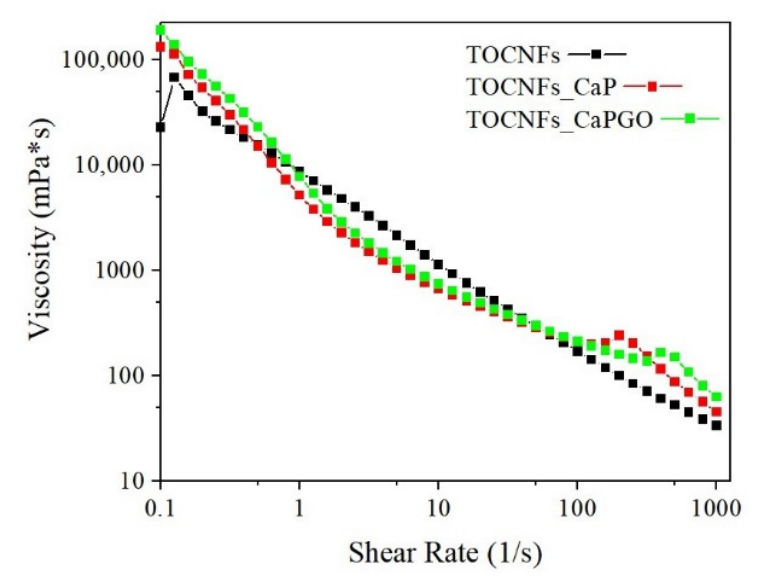

(d)

Figure 2. Viscoelastic properties of TOCNFs (black markers), TOCNFs_CaP (red markers) and TOCNFs_CaPGO (Green markers) samples. $(\mathbf{a}-\mathbf{c})$ Dynamic frequency sweeps $\left(20^{\circ} \mathrm{C}\right)$ of composites $(10 \%$ strain rate); (d) Dynamic shear rate sweep $\left(0.1\right.$ to $\left.1000 \mathrm{~s}^{-1}\right)$. 
The frequency sweep on TOCNFs samples (Figure 2a) highlights a slight increase in the moduli as the frequency increases, as usually reported for weak physically cross-linked gels [33]. In TOCNFs CaP and TOCNFs CaPGO plots (Figure 2b,c) the G' and G" curves exhibit a plateau behavior until the crossover point. Their intersect values are higher compared to TOCNFs (Figure 2a), and an increment in the moduli values is observed. $\mathrm{G}^{\prime}$ values increase from $12 \pm 7 \mathrm{~Pa}$ in TOCNFs to about $150 \pm 40 \mathrm{~Pa}$ in TOCNFs Ca and TOCNFs CaPGO. This increase of one order of magnitude suggests an increased gel strength when loaded with HA precursors. The curves remain constant until $30 \mathrm{~Hz}$ for TOCNFs CaP and TOCNFs CaPGO and until $7 \mathrm{~Hz}$ for TOCNFs samples. These results confirm the capability of the employed HA precursors to act as physical crosslinker by means of the interaction between the particles surface and the cellulose fibers. However, compared to the moduli values reported in the literature for cation-induced gelation of TOCNFs the achieved $G^{\prime}$ and $G^{\prime \prime}$ values are more than one order of magnitude lower [18], even if in this work the concentration of cellulose nanofibers is higher.

Comparing these results with other cellulose-derived hydrogels loaded with calcium phosphate, TOCNFs CaP and TOCNFs CaPGO show a broader LVR. In contrast, the storage modulus values recorded are lower compared with the average $G^{\prime}$ values found in these studies [34-36]. This is probably a consequence of the higher inorganic content considered. However, considering the valuable results achieved from injectability and mineralization tests, we decided to not explore higher inorganic content.

The viscosity of the three suspensions was measured for shear rate ranging from 0.1 to $1000 \mathrm{~s}^{-1}$ (Figure 2d). All the prepared blends exhibit a thixotropic and shear-thinning behavior in this range: the viscosity decreases significantly as the shear rate increases. This represents the typical behavior of non-Newtonian fluids. This phenomenon can be related to the weakening and disruption of the hydrogel network and the consequent release of the entrapped liquid [37]. The shear thinning behavior represents an important characteristic for injectable hydrogels.

\subsubsection{Injectability Test}

The assays were performed by loading the composite hydrogels in a sterile syringe, and then measuring the force needed to extrude the specimens through an $18 \mathrm{G}$ needle, at $20^{\circ} \mathrm{C}$ at a crosshead speed of $0.6 \mathrm{~mm} \mathrm{~s}^{-1}\left(2.28 \mathrm{~mL} \mathrm{~min}^{-1}\right)$, in order to mimic the operational condition during surgery $[30,38]$. The reasonable injection force upper limit in bone site is generally around $30 \mathrm{~N}[30,38,39]$. In addition, it is reported that the force required to inject into human tissue is 1.1 times higher than that measured in air [39]. The measured load needed to extrude freshly prepared specimens is reported in Figure 3. All the samples show a force plateau $\left(F_{\text {mean }}\right)$ after an initial force peak $\left(F_{\max }\right)$, which was associated with the force required to begin plunger movement. As expected, TOCNFs samples were more prone to be extruded $\left(\mathrm{F}_{\max }=4.52 \pm 0.28 \mathrm{~N} ; \mathrm{F}_{\text {mean }}=1.51 \pm 0.01 \mathrm{~N}\right)$, compared to TOCNFs_CaP $\left(\mathrm{F}_{\max }=4.81 \pm 0.98 \mathrm{~N} ; \mathrm{F}_{\text {mean }}=2.18 \pm 0.15 \mathrm{~N}\right)$ and TOCNFs_CaPGO $\left(\mathrm{F}_{\max }=4.47 \pm 1.02 \mathrm{~N}\right.$; $\mathrm{F}_{\text {mean }}=2.76 \pm 0.03 \mathrm{~N}$ ). These data are consistent with rheological assays, which have verified that the addition of HA precursors causes an increase in the elastic component of the hydrogels. Moreover, the loading of $\mathrm{CaP}$ and $\mathrm{CaPGO}$ into the TOCNFs dispersions do not cause obstruction in the needle. In order to evaluate the influence of the thixotropic behavior of the composite hydrogels on injectability, the same measurements were repeated after letting the specimens set for $48 \mathrm{~h}$ in the syringes (Figure $3 \mathrm{~b}$ ). As expected, in all cases an increase of the measured forces was recorded (TOCNFs $F_{\max }=4.02 \pm 0.62 \mathrm{~N}$, $\mathrm{F}_{\text {mean }}=2.34 \pm 0.12 \mathrm{~N}$; TOCNFs CaP $\mathrm{F}_{\max }=4.99 \pm 0.03 \mathrm{~N}, \mathrm{~F}_{\text {mean }}=4.37 \pm 0.03 \mathrm{~N}$ and TOCNFs CaPGO F $\left.F_{\text {max }}=3.91 \pm 0.15 \mathrm{~N}, \mathrm{~F}_{\text {mean }}=3.42 \pm 0.40 \mathrm{~N}\right)$. All the recorded loads resulted to be far below the $30 \mathrm{~N}$ limit, indicating that the proposed composites can be easily injected in vivo at a reasonable rate. Similar injectable hydrogels reported in the literature often require higher load values in order to be successfully extruded and/or lower extrusion speeds $[30,39]$. As an example, Safwat et al. recently reported TOCNFs hydrogels loaded with a high amount of calcium phosphates which can be extruded trough a $18 \mathrm{G}$ 
needle at $1.50 \mathrm{~N}$; however, the extrusion speed was set to $1 \mathrm{~mm} \mathrm{~min}^{-1}$, which is 36 times lower than the extrusion rate employed in this work, limiting the clinical applicability of the proposed composite [36].

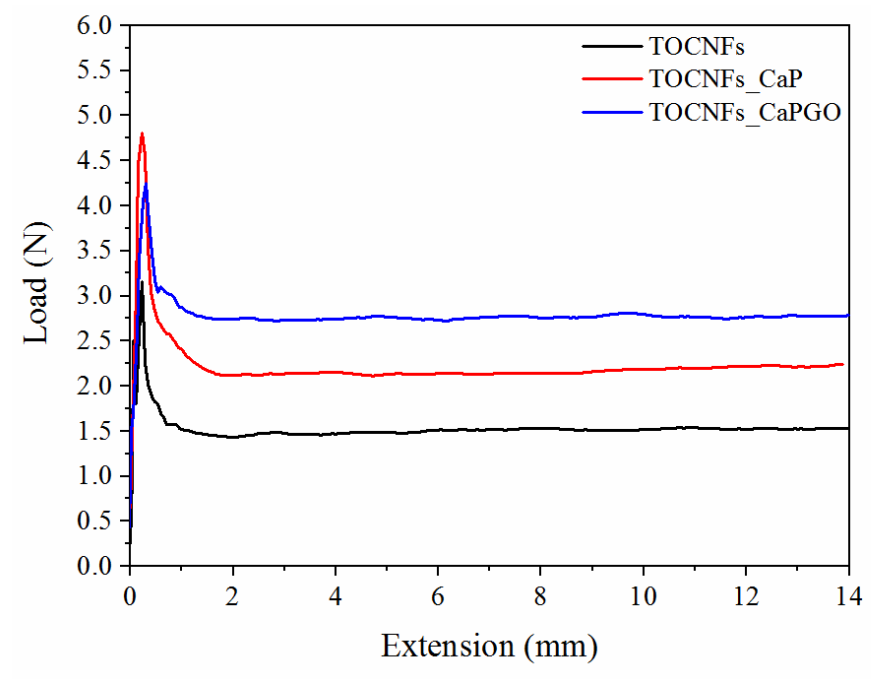

(a)

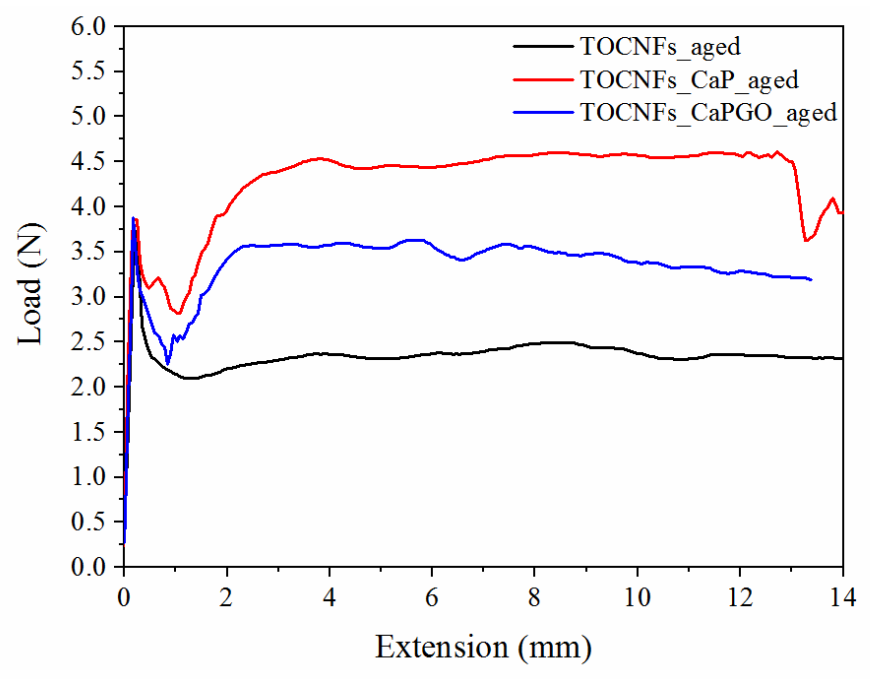

(b)

Figure 3. Injectability test: comparison between: (a) fresh prepared samples and (b) $48 \mathrm{~h}$ aged samples. TOCNFs (black line), TOCNFs_CaP (red line) and TOCNFs_CaPGO (blue line) were extruded through a $18 \mathrm{G}$ needle at $20^{\circ} \mathrm{C}$ at a crosshead speed of $0.6 \mathrm{~mm} \mathrm{~s}^{-1}\left(2.28 \mathrm{~mL} \mathrm{~min}^{-1}\right)$ measuring the force needed for the process.

\subsection{In Vitro Test}

\subsubsection{Swelling Test}

Swelling tests were carried out in order to determine the weight variation and the stability of the biocomposites. Samples were immersed in sterile culture medium (DMEM, enriched with antibiotics and sodium azide) and then incubated at $37^{\circ} \mathrm{C}$. At progressive intervals of $15 \mathrm{~min}, 1 \mathrm{~h}$ and then 1,3, 7, and 34 days, the culture medium was removed, and the samples were weighed. The results of the swelling test are reported in Figure 4. In case of unloaded TOCNFs dispersions, the samples were totally dissolved after the first time point, while for particles embedded samples, a rapid initial increase was observed within the first $15 \mathrm{~min}$ ( 0.01 days). After 1 day, all samples registered the maximum increase in weight reaching values of $58 \%$ for TOCNFs CaP, and $68 \%$ for TOCNFs CaPGO. Between 1 and 3 days, a weight loss is observed denoting a possible release of the water used in the gel realization process which is gradually replaced by the culture medium. After 7 days and until the end of the experiment, a further loss in weight was recorded, probably due to a gradual loss and breakage of material during the replacement phase of the culture medium. Nevertheless, the results suggest a good stability of the material. 


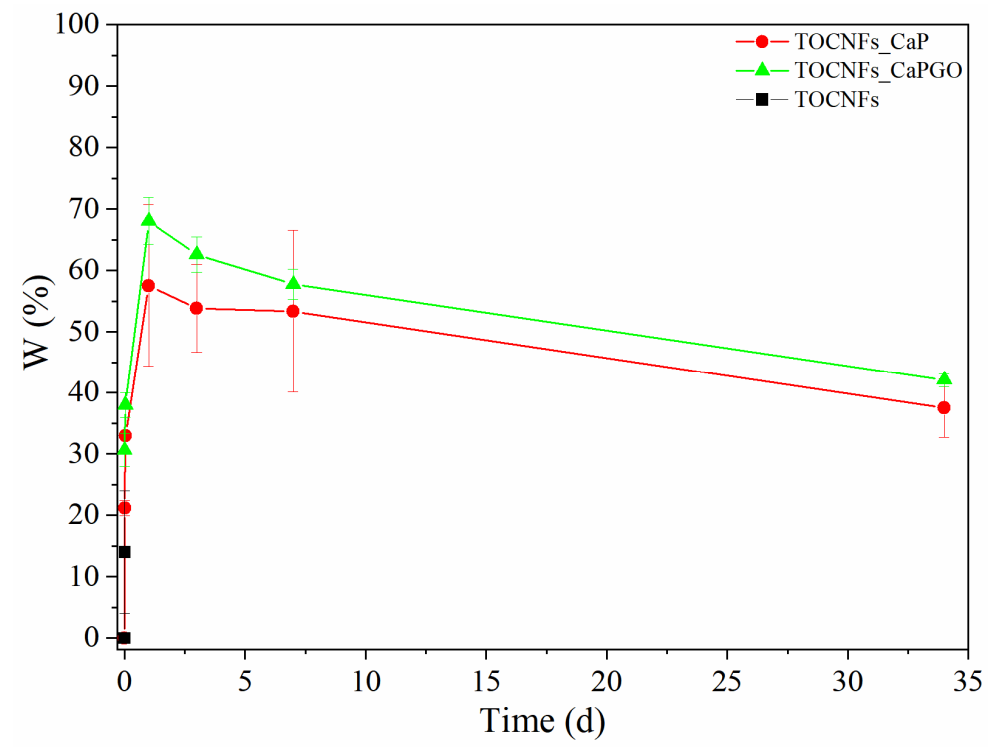

Figure 4. Swelling Test on TOCNFs (black), TOCNFs CaP (red) and TOCNFs CaPGO (green) was performed by immersing the samples in sterile culture medium at $37^{\circ} \mathrm{C}$ and carefully weigh the samples at different time steps.

\subsubsection{In Vitro Mineralization Test}

Mineralization assays were carried out by aging the hydrogels in simulated body fluid $1.5 \times(\mathrm{SBF})$ at $37^{\circ} \mathrm{C}$ up to 28 days, and the growth of hydroxyapatite crystals was evaluated as a marker of efficient mineralization. At each time point $(7,14,21$ and 28 days) the samples were freeze-dried and then analyzed by means of XRD and SEM microscopy. The effect of mineralization can be observed also from a macroscopic point of view; indeed, the hydrogels become more opaque and stiffer after a few days.

XRD patterns for each sample at all the time points are reported in Figure $5 \mathrm{a}-\mathrm{c}$. In all cases, the XRD diffractograms are dominated by the presence of $\mathrm{NaCl}$ and Tris(hydroxymethyl) methylamine (Tris), pattern. $\mathrm{NaCl}$ was responsible for peaks at $27.5^{\circ}, 31.7^{\circ}, 45.6^{\circ}$ and $56.6^{\circ}$, while Tris signals were present at $10.6^{\circ}, 15.3^{\circ}, 21.6^{\circ}, 23.5^{\circ}$ and $50.3^{\circ}$. The typical peaks of crystalline cellulose $\mathrm{I} \beta$ were found at $2 \theta$ of $22.5^{\circ}, 16.5^{\circ}$ and $14.7^{\circ}$ [40].

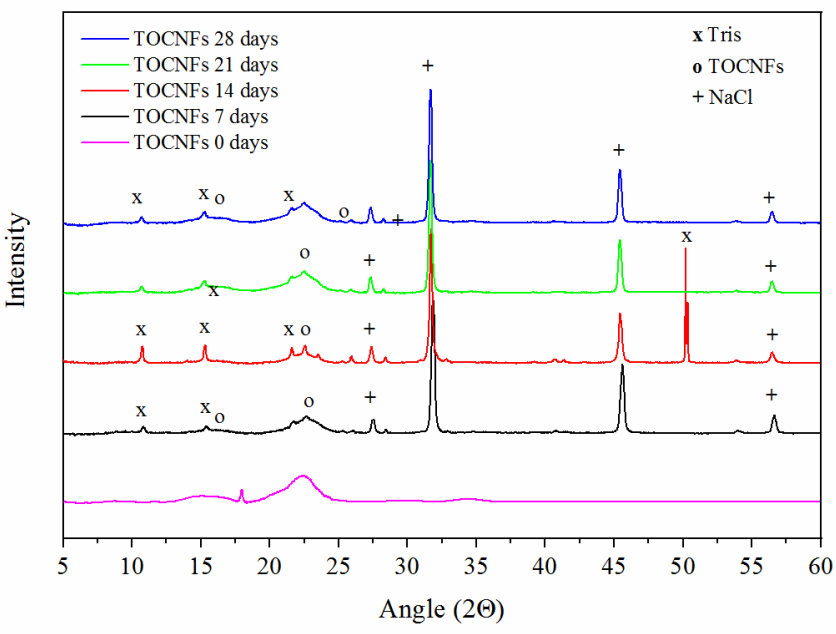

(a)

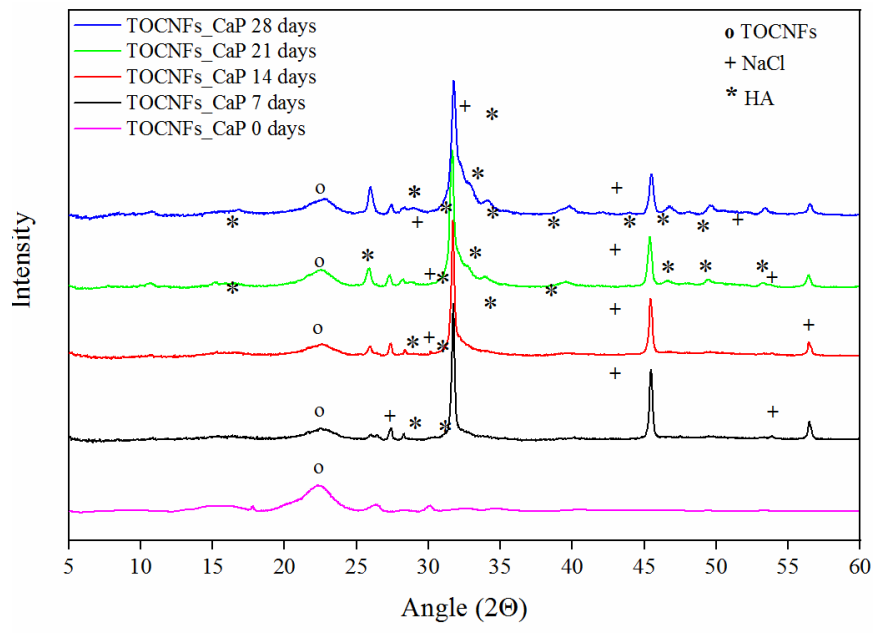

(b)

Figure 5. Cont. 


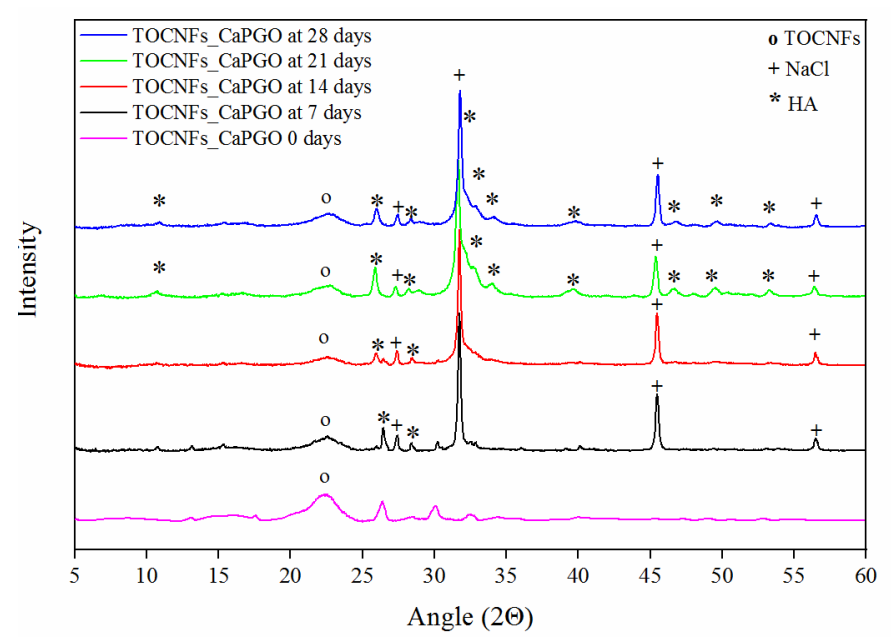

(c)

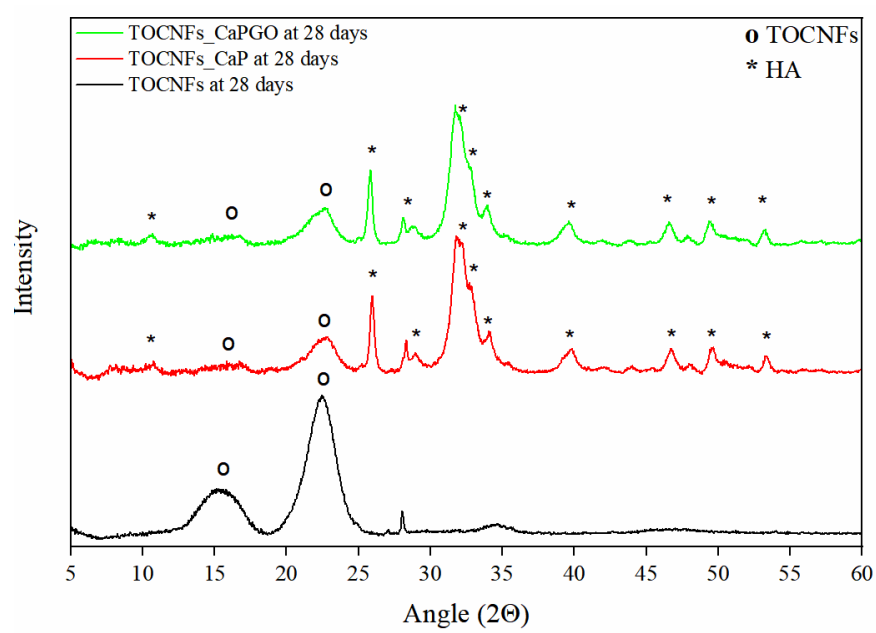

(d)

Figure 5. XRD diffraction patterns of nanocomposites hydrogels after 7, 14, 21 and 28 days of different specimens TOCNFs (a), TOCNFs CaP (b), TOCNFs CaPGO (c), and XRD of mineralized hydrogels at 28 days after water rinsing (d).

In case of TOCNFs samples (Figure 5a) no evidence of apatite formation can be observed. However, in the diffractograms of TOCNFs CaP (Figure 5b) and TOCNFs CaPGO (Figure 5c) samples it was possible to identify the typical diffraction pattern of hydroxyapatite $\left(\mathrm{Ca}_{10}\left(\mathrm{PO}_{4}\right)_{6}(\mathrm{OH})_{2}, \mathrm{HA}\right)$ at $10.6^{\circ}, 25.9^{\circ}, 28.3^{\circ}, 31.8^{\circ}, 32.8^{\circ}, 34.0^{\circ}, 39.6^{\circ}, 46.7^{\circ}$, $49.5^{\circ}$ and $53.2^{\circ}$ [32]. In these cases, the presence of HA can be observed even after the first time point ( 7 days). Interestingly, the HA peaks at $2 \theta 31.8^{\circ}, 32.2^{\circ}, 32.9^{\circ}$ and $34.0^{\circ}$ appear as a single, broad and poorly defined peak suggesting the nanometric dimensions of the hydroxyapatite crystallite [32]. In order to remove the interference of $\mathrm{NaCl}$ and Tris and to verify that HA crystals are tightly embedded in the TOCNFs matrix, after 28 days the hydrogels were rinsed in pure water and the XRD measurements were repeated (Figure 5d). After this washing, the HA crystalline phase becomes more evident confirming that the TOCNFs CaP and TOCNFs CaPGO were successfully mineralized, while hydrogels made of pure TOCNFs do not seem to mineralize at all.

These results were also confirmed by means of SEM microscopy (Figure 6a-f). In TOCNFs samples, before (Figure 6a) and after (Figure $6 \mathrm{~b}$ ) the mineralization, only the cellular structures typical of lyophilized hydrogels can be observed, without any evidence of formation of HA on its surface. In contrast, in samples TOCNFs CaP (Figure 6c) and TOCNFs CaPGO (Figure 6e) acquired before the mineralization experiments, the HA precursors ( $\mathrm{CaP}$ and $\mathrm{CaPGO}$ ) homogeneously dispersed on the cellular structures can be observed. After the mineralization of these samples, the hydrogels structures were covered by spherical HA nanoparticles interlinked with each other (Figure $6 \mathrm{~d}, \mathrm{f}$ ), having an average size in the range of $50 \mathrm{~nm}-150 \mathrm{~nm}$, in good accordance with the literature [41,42]. 


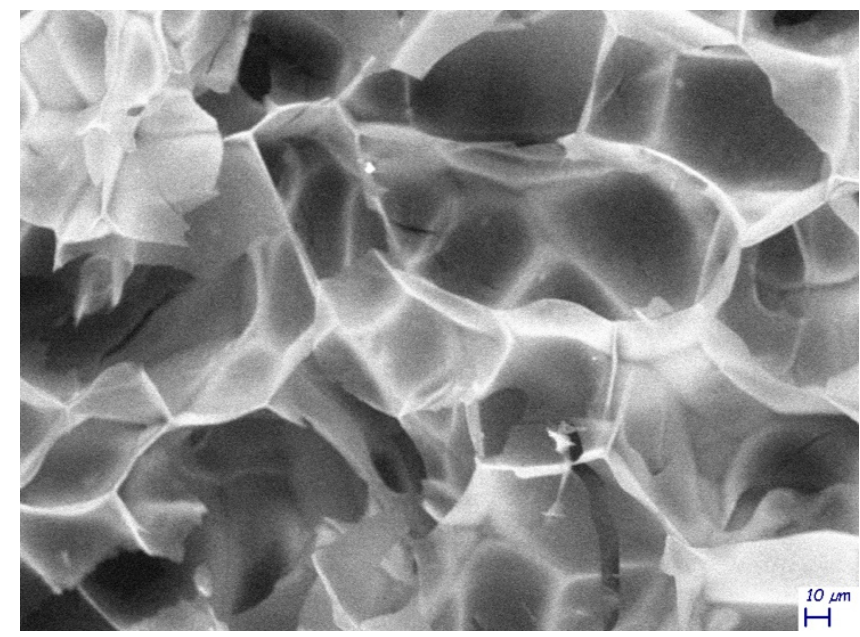

(a)

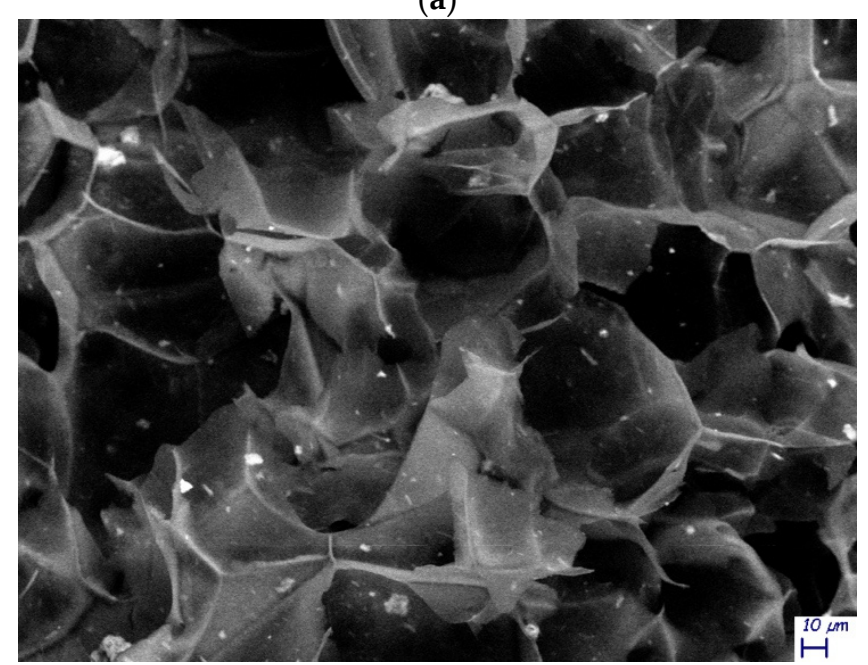

(c)

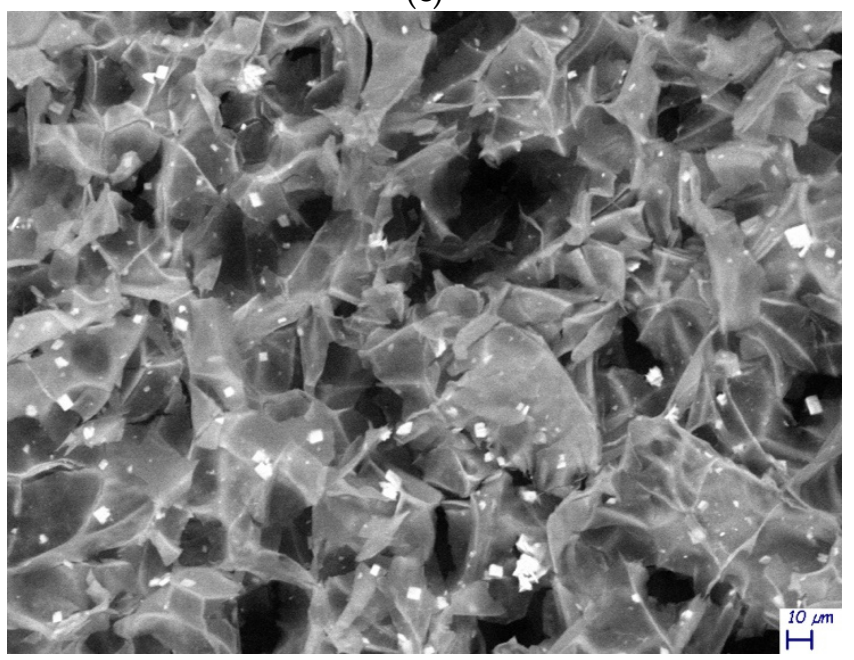

(e)

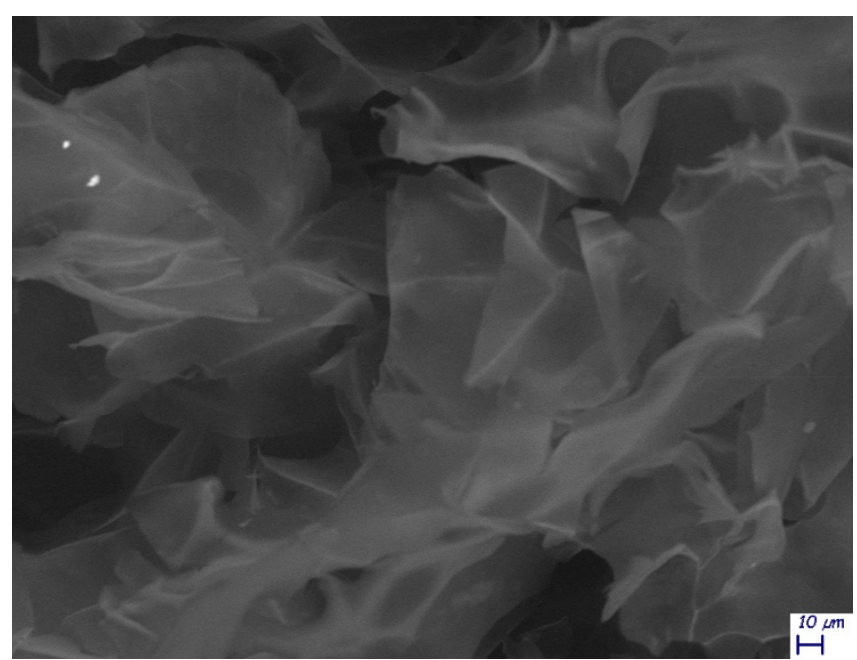

(b)

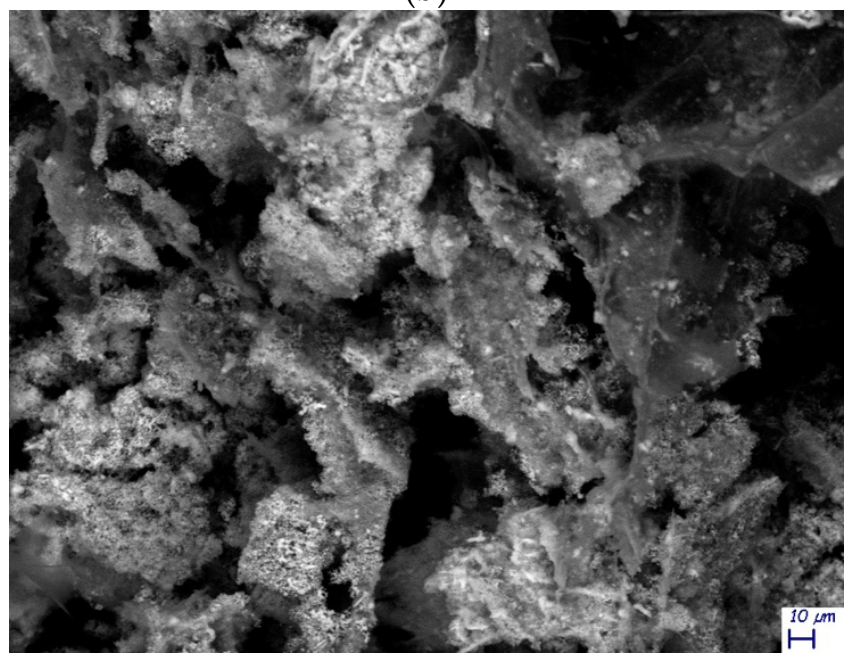

(d)

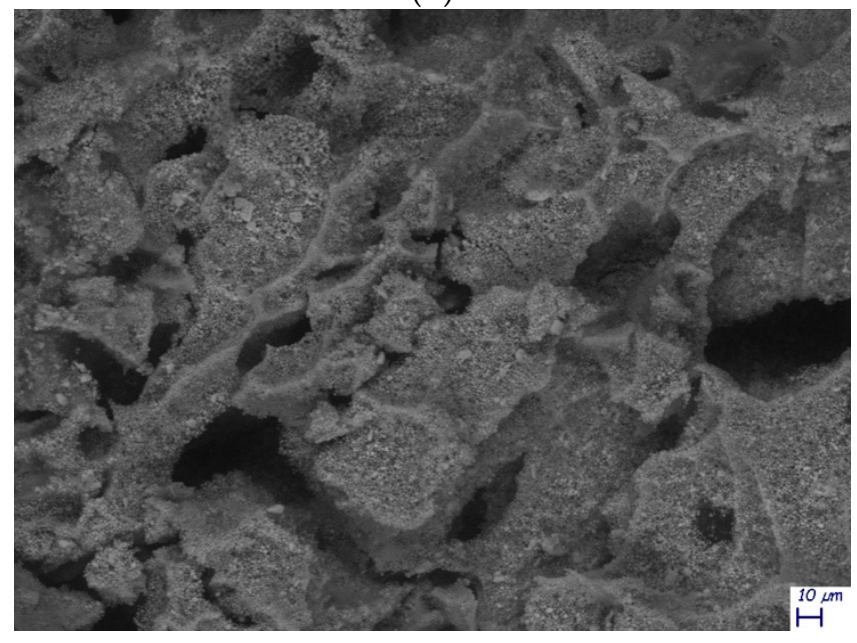

(f)

Figure 6. SEM images of: (a) TOCNFs before mineralization; (b) TOCNFs after mineralization (28 d) and washing step; (c) TOCNFs CaP before mineralization; (d) TOCNFs CaP after mineralization (28 d) and washing step; (e) TOCNFs CaPGO before mineralization; (f) TOCNFs CaPGO after mineralization (28 d) and washing step. Scalebar $10 \mu \mathrm{m}$. In Figures S6 and S7 are reported SEM images of mineralized TOCNFs CaP and TOCNFs CaPGO acquired at higher magnification. 


\subsubsection{Cytotoxicity Assay}

In Figure 7, we reported the metabolic activity of cells cultured in contact with eluates, evaluated by Alamar Blue assay. The viability of cells incubated with material extracts (eluates) was comparable or higher than those of cells cultured under standard conditions. All values are above $70 \%$, and the limit to consider samples non cytotoxic was determined according to the EN ISO 10993-12 standard. These results demonstrated that TOCNFs-based hydrogels do not release any cytotoxic compounds. Moreover, no significant differences were detected between TOCNFs $\mathrm{CaP}$ and TOCNFs CaPGO, indicating that, for all time points of incubation, the inorganic components did not affect SAOS-2 cell viability.

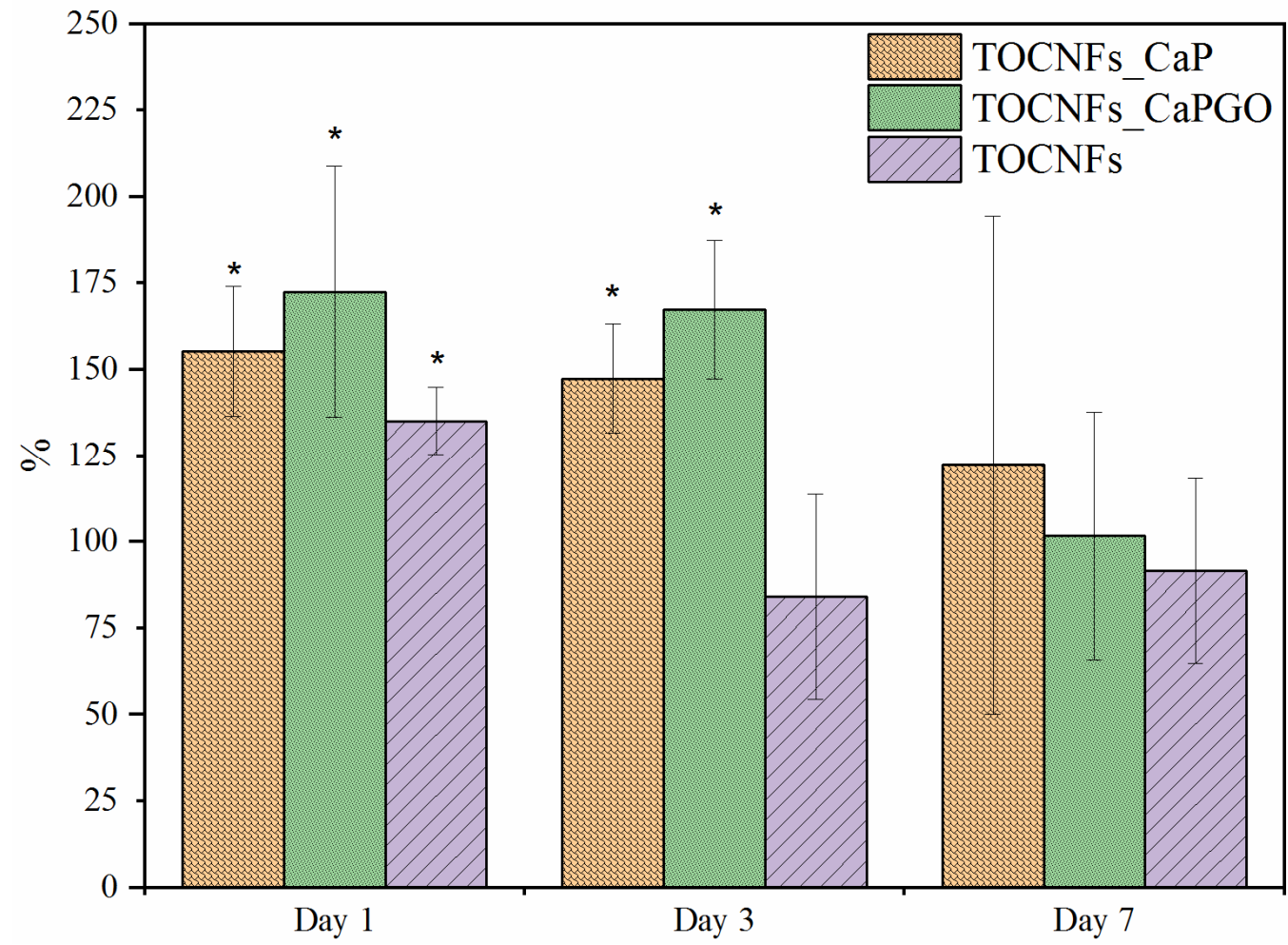

Figure 7. Viability of SAOS-2 cells incubated with eluates obtained from different hydrogels. * Statistically significant differences were evaluated by means of $\mathrm{t}$-student test $(p<0.05)$.

\section{Conclusions}

The use of cellulose in tissue engineering is often limited due to the lack of an adhesive site in cells. The possibility of fabricating biocomposites could overcome this drawback. In this work, we started to investigate composite hydrogels that were successfully obtained with both CaP and CaPGO. Their physico-chemical properties can be enhanced through the addition of the inorganic phases within the matrix. These properties can be easily modulated by modifying the amount of inorganic components, depending on the final application. Hydrogels showed a good injectability; indeed, they can be easily extruded in typical conditions employed during surgery practice since relative low loads $(1.5-5 \mathrm{~N})$ are needed in order to inject about $2.3 \mathrm{~mL}$ of hydrogel in one minute. At the same time, the proposed biocomposites show a good bioactivity; in fact, both $\mathrm{CaP}$ and $\mathrm{CaPGO}$ hydrogels were able to induce the mineralization process, and an HA layer was observed on composite samples after SBF immersion. This result suggests that the proposed hydrogel can be easily injected in bone defects. Finally, no cytotoxic effect, due to the release of any component from the hydrogel, was shown in any of the samples. However, further investigation on biocompatibility would be necessary to understand potential applications in bone tissue regeneration. 
Supplementary Materials: The following are available online at https:/ / www.mdpi.com/article/10 $.3390 /$ ma14164511/s1, Figure S1: Rheological characterization: determination of LVR. Strain sweep in the range $0.01-100 \%$ with constant frequency at $1 \mathrm{~Hz}$, Figure S2: Schematic representation of custom injectability ex-perimental setup, Figure S3: FT-IR of pristine cellulose (black line), oxidized cellulose (red line), TOCNFs (blue line), Figure S4: (a) Nanoparticles aspect, (b) FT-IR of CaP (red line) and CaPGO (green line) nanoparticles, (c) XRD diffractogram of CaP nanoparticles (d) XRD diffractogram of CaPGO nanoparticles, Figure S5: (a) TG-DTA curves of (a) TOCNFs, (b) TOCNFs_CaP, (c) TOCNFs-CaPGO, Figure S6: SEM images of TOCNFs CaP after mineralization (28 d) and washing step, Figure S7: SEM images of TOCNFs CaPGO after mineralization (28 d) and washing step.

Author Contributions: Conceptualization, A.F. and L.A.; methodology, A.F. and L.A.; investigation, C.L. and C.G.; writing-original draft preparation, A.F., C.L. and C.G.; writing-review and editing, A.F., M.G.R. and L.A.; funding acquisition, M.G.R. and L.A. All authors have read and agreed to the published version of the manuscript.

Funding: This research was funded by the Ministero dell'Istruzione, dell'Università e della Ricerca (MIUR), grant number PRIN ‘ACTION’2017SZ5WZB_002.

Institutional Review Board Statement: Not applicable.

Informed Consent Statement: Not applicable.

Data Availability Statement: Data is contained within the article or supplementary material.

Conflicts of Interest: The authors declare no conflict of interest. The funders had no role in the design of the study; in the collection, analyses, or interpretation of data; in the writing of the manuscript, or in the decision to publish the results.

\section{References}

1. Mehrali, M.; Thakur, A.; Pennisi, C.P.; Talebian, S.; Arpanaei, A.; Nikkhah, M.; Dolatshahi-Pirouz, A. Nanoreinforced Hydrogels for Tissue Engineering: Biomaterials that are Compatible with Load-Bearing and Electroactive Tissues. Adv. Mater. 2017, 29, 1603612. [CrossRef]

2. Mauri, E.; Naso, D.; Rossetti, A.; Borghi, E.; Ottaviano, E.; Griffini, G.; Masi, M.; Sacchetti, A.; Rossi, F. Design of polymer-based antimicrobial hydrogels through physico-chemical transition. Mater. Sci. Eng. C 2019, 103, 109791. [CrossRef] [PubMed]

3. Vismara, I.; Papa, S.; Veneruso, V.; Mauri, E.; Mariani, A.; De Paola, M.; Affatato, R.; Rossetti, A.; Sponchioni, M.; Moscatelli, D.; et al. Selective Modulation of A1 Astrocytes by Drug-Loaded Nano-Structured Gel in Spinal Cord Injury. ACS Nano 2020, 14, 360-371. [CrossRef]

4. Mauri, E.; Micotti, E.; Rossetti, A.; Melone, L.; Papa, S.; Azzolini, G.; Rimondo, S.; Veglianese, P.; Punta, C.; Rossi, F.; et al. Microwave-assisted synthesis of TEMPO-labeled hydrogels traceable with MRI. Soft Matter 2018, 14, 558-565. [CrossRef]

5. Hoare, T.R.; Kohane, D.S. Hydrogels in drug delivery: Progress and challenges. Polymer 2008, 49, 1993-2007. [CrossRef]

6. Qi, H. Novel Functional Materials Based on Cellulose; Springer International Publishing: Cham, Switzerland, 2017.

7. Sunasee, R.; Hemraz, U. Synthetic Strategies for the Fabrication of Cationic Surface-Modified Cellulose Nanocrystals. Fibers 2018, 6, 15. [CrossRef]

8. Gallo Stampino, P.; Riva, L.; Punta, C.; Elegir, G.; Bussini, D.; Dotelli, G. Comparative Life Cycle Assessment of Cellulose Nanofibres Production Routes from Virgin and Recycled Raw Materials. Molecules 2021, 26, 2558. [CrossRef]

9. Ghasemlou, M.; Daver, F.; Ivanova, E.P.; Habibi, Y.; Adhikari, B. Surface Modifications of Nanocellulose: From Synthesis to High-Performance Nanocomposites. Prog. Polym. Sci. 2021, 119, 101418. [CrossRef]

10. Pierre, G.; Punta, C.; Delattre, C.; Melone, L.; Dubessay, P.; Fiorati, A.; Pastori, N.; Galante, Y.M.; Michaud, P. TEMPO-mediated oxidation of polysaccharides: An ongoing story. Carbohydr. Polym. 2017, 165, 71-85. [CrossRef]

11. Da Silva Perez, D.; Montanari, S.; Vignon, M.R. TEMPO-mediated oxidation of cellulose III. Biomacromolecules 2003, 4, 1417-1425. [CrossRef]

12. Saito, T.; Isogai, A. TEMPO-Mediated Oxidation of Native Cellulose. The Effect of Oxidation Conditions on Chemical and Crystal Structures of the Water-Insoluble Fractions. Biomacromolecules 2004, 5, 1983-1989. [CrossRef]

13. Okita, Y.; Saito, T.; Isogai, A. Entire Surface Oxidation of Various Cellulose Microfibrils by TEMPO-Mediated Oxidation. Biomacromolecules 2010, 11, 1696-1700. [CrossRef]

14. Isogai, A.; Saito, T.; Fukuzumi, H. TEMPO-oxidized cellulose nanofibers. Nanoscale 2011, 3, 71-85. [CrossRef]

15. Fiorati, A.; Contessi Negrini, N.; Baschenis, E.; Altomare, L.; Faré, S.; Giacometti Schieroni, A.; Piovani, D.; Mendichi, R.; Ferro, M.; Castiglione, F.; et al. TEMPO-Nanocellulose/Ca2+ Hydrogels: Ibuprofen Drug Diffusion and In Vitro Cytocompatibility. Materials 2020, 13, 183. [CrossRef] 
16. Valencia, L.; Nomena, E.M.; Monti, S.; Rosas-Arbelaez, W.; Mathew, A.P.; Kumar, S.; Velikov, K.P. Multivalent ion-induced re-entrant transition of carboxylated cellulose nanofibrils and its influence on nanomaterials' properties. Nanoscale 2020, 12, 15652-15662. [CrossRef]

17. Zander, N.E.; Dong, H.; Steele, J.; Grant, J.T. Metal Cation Cross-Linked Nanocellulose Hydrogels as Tissue Engineering Substrates. ACS Appl. Mater. Interfaces 2014, 6, 18502-18510. [CrossRef] [PubMed]

18. Dong, H.; Snyder, J.F.; Williams, K.S.; Andzelm, J.W. Cation-Induced Hydrogels of Cellulose Nanofibrils with Tunable Moduli. Biomacromolecules 2013, 14, 3338-3345. [CrossRef]

19. Hickey, R.J.; Pelling, A.E. Cellulose Biomaterials for Tissue Engineering. Front. Bioeng. Biotechnol. 2019, 7, 45. [CrossRef]

20. Basu, A.; Heitz, K.; Strømme, M.; Welch, K.; Ferraz, N. Ion-crosslinked wood-derived nanocellulose hydrogels with tunable antibacterial properties: Candidate materials for advanced wound care applications. Carbohydr. Polym. 2018, 181, 345-350. [CrossRef]

21. Dutta, S.R.; Passi, D.; Singh, P.; Bhuibhar, A. Ceramic and non-ceramic hydroxyapatite as a bone graft material: A brief review. Irish J. Med. Sci. 2015, 184, 101-106. [CrossRef]

22. Fathi, M.H.; Hanifi, A.; Mortazavi, V. Preparation and bioactivity evaluation of bone-like hydroxyapatite nanopowder. J. Mater. Process. Technol. 2008, 202, 536-542. [CrossRef]

23. Nasrollahzadeh, M.; Babaei, F.; Fakhri, P.; Jaleh, B. Synthesis, characterization, structural, optical properties and catalytic activity of reduced graphene oxide/copper nanocomposites. RSC Adv. 2015, 5, 10782-10789. [CrossRef]

24. Raucci, M.G.; Giugliano, D.; Longo, A.; Zeppetelli, S.; Carotenuto, G.; Ambrosio, L. Comparative facile methods for preparing graphene oxide-hydroxyapatite for bone tissue engineering. J. Tissue Eng. Regen. Med. 2017, 11, 2204-2216. [CrossRef]

25. Burnett, M.; Abuetabh, Y.; Wronski, A.; Shen, F.; Persad, S.; Leng, R.; Eisenstat, D.; Sergi, C. Graphene Oxide Nanoparticles Induce Apoptosis in wild-type and CRISPR/Cas9-IGF/IGFBP3 knocked-out Osteosarcoma Cells. J. Cancer 2020, 11, 5007-5023. [CrossRef]

26. Doebelin, N.; Kleeberg, R. Profex: A graphical user interface for the Rietveld refinement program BGMN. J. Appl. Crystallogr. 2015, 48, 1573-1580. [CrossRef]

27. Schneider, C.A.; Rasband, W.S.; Eliceiri, K.W. NIH Image to ImageJ: 25 years of image analysis. Nat. Methods 2012, 9, 671-675. [CrossRef]

28. Geng, L.; Peng, X.; Zhan, C.; Naderi, A.; Sharma, P.R.; Mao, Y.; Hsiao, B.S. Structure characterization of cellulose nanofiber hydrogel as functions of concentration and ionic strength. Cellulose 2017, 24, 5417-5429.

29. Rashad, A.; Mustafa, K.; Heggset, E.B.; Syverud, K. Cytocompatibility of Wood-Derived Cellulose Nanofibril Hydrogels with Different Surface Chemistry. Biomacromolecules 2017, 18, 1238-1248.

30. Yasmeen, S.; Lo, M.K.; Bajracharya, S.; Roldo, M. Injectable Scaffolds for Bone Regeneration. Langmuir 2014, 30, 12977-12985.

31. Kokubo, T.; Takadama, H. How useful is SBF in predicting in vivo bone bioactivity? Biomaterials 2006, 27, 2907-2915. [CrossRef]

32. Lopes, C.C.; Pinheiro, W.A.; Navarro da Rocha, D.; Neves, J.G.; Correr, A.B.; Ferreira, J.R.M.; Barbosa, R.M.; Soares, J.R.F.; Santos, J.L.; Prado da Silva, M.H. Nanocomposite powders of hydroxyapatite-graphene oxide for biological applications. Ceram. Int. 2021, 47, 7653-7665. [CrossRef]

33. Mendoza, L.; Batchelor, W.; Tabor, R.F.; Garnier, G. Gelation mechanism of cellulose nanofibre gels: A colloids and interfacial perspective. J. Colloid Interface Sci. 2018, 509, 39-46. [CrossRef]

34. Oğuz, Ö.D.; Ege, D. Rheological and mechanical properties of thermoresponsive methylcellulose/calcium phosphate-based injectable bone substitutes. Materials 2018, 11, 604. [CrossRef]

35. Basu, P.; Saha, N.; Saha, P. Swelling and rheological study of calcium phosphate filled bacterial cellulose-based hydrogel scaffold. J. Appl. Polym. Sci. 2020, 137, 48522. [CrossRef]

36. Safwat, E.; Hassan, M.L.; Saniour, S.; Zaki, D.Y.; Eldeftar, M.; Saba, D.; Zazou, M. Injectable TEMPO-oxidized nanofibrillated cellulose/biphasic calcium phosphate hydrogel for bone regeneration. J. Biomater. Appl. 2018, 32, 1371-1381. [CrossRef] [PubMed]

37. Abouzeid, R.E.; Khiari, R.; Salama, A.; Diab, M.; Beneventi, D.; Dufresne, A. In situ mineralization of nano-hydroxyapatite on bifunctional cellulose nanofiber/polyvinyl alcohol/sodium alginate hydrogel using 3D printing. Int. J. Biol. Macromol. 2020, 160, 538-547. [CrossRef] [PubMed]

38. Burckbuchler, V.; Mekhloufi, G.; Giteau, A.P.; Grossiord, J.L.; Huille, S.; Agnely, F. Rheological and syringeability properties of highly concentrated human polyclonal immunoglobulin solutions. Eur. J. Pharm. Biopharm. 2010, 76, 351-356. [CrossRef]

39. Kim, M.H.; Kim, B.S.; Park, H.; Lee, J.; Park, W.H. Injectable methylcellulose hydrogel containing calcium phosphate nanoparticles for bone regeneration. Int. J. Biol. Macromol. 2018, 109, 57-64. [CrossRef] [PubMed]

40. Jiang, F.; Hsieh, Y.-L. Self-assembling of TEMPO Oxidized Cellulose Nanofibrils As Affected by Protonation of Surface Carboxyls and Drying Methods. ACS Sustain. Chem. Eng. 2016, 4, 1041-1049. [CrossRef]

41. Yin, N.; Chen, S.-Y.; Ouyang, Y.; Tang, L.; Yang, J.-X.; Wang, H.-P. Biomimetic mineralization synthesis of hydroxyapatite bacterial cellulose nanocomposites. Prog. Nat. Sci. Mater. Int. 2011, 21, 472-477. [CrossRef]

42. Grande, C.J.; Torres, F.G.; Gomez, C.M.; Carmen Bañó, M. Nanocomposites of bacterial cellulose/hydroxyapatite for biomedical applications. Acta Biomater. 2009, 5, 1605-1615. [CrossRef] [PubMed] 